\title{
A FORMAÇÃO DE PROFESSORES E O RENDIMENTO ESCOLAR: UMA ANÁLISE CRÍTICA
}

Marijane Zanotto

Rosane Toebe Zen

\section{RESUMO:}

$\mathrm{O}$ artigo tem como objetivo tecer um panorama da educação no município de Francisco Beltrão-PR sobre a formação de professores e o rendimento escolar nas séries iniciais do ensino fundamental da rede pública municipal no período de 1988 a 2006. Na metodologia utilizou-se de pesquisa empírica, realizada através de coleta de dados relativos ao rendimento escolar: matrícula, frequência, aprovação, reprovação e à qualificação docente. A análise dos dados coletados foi realizada no diálogo com autores que se situam na perspectiva crítica da educação, entre os quais: Dermeval Saviani, István Mészáros, Paulo Sergio Tumolo, José Claudinei Lombardi, Lizia Helena Nagel, Newton Duarte e Adolfo Sánches Vázquez. No que tange aos resultados da pesquisa, se identifica que no plano formal, a educação pública oferecida à população no município está assentada aparentemente numa situação que se avizinha da perfeição: grande parte dos professores está bem qualificada, os investimentos educacionais são cumpridos, a composição da educação no IDH do município está próxima do topo $(0,918$ na escala que vai até 1,0$)$. Entretanto, a análise mais pormenorizada revela que a avaliação do rendimento escolar, pelos mecanismos externos a escola, como exemplo, o Saeb e a Prova Brasil, tem orientado o trabalho docente. Para atingir os resultados satisfatórios nos índices, as escolas relegam os seus projetos políticos-pedagógicos, voltando suas práticas às demandas emanadas destas avaliações externas. Compreende-se que a tarefa legal determinada pela Constituição Federal de 1988 no que refere à obrigação do Estado em garantir o acesso e a gratuidade ao ensino fundamental, e da LDB 9394/96, no que refere à qualificação profissional dos docentes da Educação Básica, vem se efetivando no município. Porém, vale considerar que melhorias nos índices quantitativos nem sempre revelam melhorias qualitativas na educação.

Palavras-chave: Marxismo e educação. Formação de professores. Rendimento escolar.

\section{TRAINING OF TEACHERS AND SCHOOL PERFORMANCE: A CRITICAL ANALYSIS}

\begin{abstract}
The article aims to propose an overview of education in the municipality of Francisco Beltrão-PR on teacher training and academic achievement in early grades of elementary school of public health system in the period 1988 to 2006. In the methodology we used for empirical research, conducted by collecting data on school performance: enrollment, attendance, approval, disapproval and teaching qualification. The data analysis was performed in dialogue with authors who are in the critical perspective of education, including: Dermeval Saviani, István Mészáros, Tumolo Paulo Sergio, Jose Claudinei Lombardi Lizia Helena Nagel, Newton Duarte and Sánches Adolfo Vazquez. With regard to results, which is identified on the formal, public education offered to the population in the city is apparently sitting in a situation that is approaching perfection: many teachers are well qualified educational investments are completed, the composition education in the municipality's HDI is near the top (0.918 on the scale that goes up to 1.0). However, more
\end{abstract}


detailed analysis reveals that the evaluation of school performance, by mechanisms outside the school as an example, and Saeb Brazil Test, has guided the work of teachers. To achieve satisfactory results in the index schools relegate their political projects, teaching, turning their practices to the demands emanating from these external evaluations. It is understood that the legal task specified by the Constitution of 1988 as regards the State's obligation to ensure access to primary education and gratuity, and LDB 9394/96, as regards the professional qualification of teachers of Basic Education, has is effecting the city. However, it is considered that improvements in quantitative indices do not always reveal qualitative improvements in education.

Keywords: Marxism and education. Teacher training. School performance.

\section{1 - Introdução}

A proposta deste $\operatorname{artigo~}^{1}$ consiste em tecer um panorama educacional no sentido de contextualizar e compreender a educação no município de Francisco Beltrão - PR no que se refere à formação de professores e ao rendimento escolar nas séries iniciais do ensino fundamental da rede municipal, no período correspondente aos anos de 1988 a 2006, elencando elementos referentes ao processo de universalização do ensino fundamental. A justificativa para este recorte temporal reside no fato de que o ano de 1988 é marcado pela promulgação da Constituição Federal, onde ficou estabelecida a obrigatoriedade do Estado em ofertar gratuitamente o ensino fundamental. Depois da Constituição, outro marco da história recente da educação brasileira está relacionado à aprovação da LDB 9394/96, que, além de reforçar a necessidade da oferta e acesso gratuito da população ao ensino fundamental, também estabelece a elevação do nível da formação dos profissionais da educação, assim como também lhes garante o direito à formação continuada.

Para a realização da pesquisa, a coleta de dados se revelou mais difícil do que o previsto. A Secretaria Municipal de Educação de Francisco Beltrão - PR não dispõem dos dados relativos à matrícula, evasão e repetência dos seus alunos no período de 1988 a 1997. Os dados completos só estão disponíveis a partir do ano de 1998. Talvez não seja coincidência que estas informações tenham sido cadastradas justamente a partir da aplicação da lei do $\mathrm{FUNDEF}^{2}$, por meio do qual o ensino fundamental passa a ser provido substancialmente com recursos deste fundo, distribuídos de acordo com as projeções de matrícula para o ano seguinte. Como este recurso é recebido pelos estados e municípios a partir do número de alunos atendidos pelas respectivas redes de ensino, e também como a criação deste fundo objetivou a universalização do ensino fundamental, estados e municípios que não tinham por prática manter atualizados os dados relativos à matrícula, evasão e repetência, passaram a fazê-lo, quer seja para comprovar a existência dos alunos atendidos, quer seja para apresentar relatórios às instâncias superiores no sentido de indicar melhora do atendimento.

Com relação ao número professores e à formação destes no período de 1988 a 2006, os dados disponibilizados pela Secretaria Municipal de Educação de Francisco Beltrão - PR são ainda mais restritos: o acompanhamento e o registro das informações relativas à formação dos professores ocorreram somente a partir de 2005.

Sendo assim, este texto tecerá algumas considerações acerca dos dados disponíveis: o Plano Municipal de Educação de Francisco Beltrão - PR, que apresenta o diagnóstico da situação educacional do município, as conquistas e as fragilidades do atendimento; dados do IPARDES (2009), dos quais foram apropriadas as informações disponíveis no Caderno Estatístico do Município de Francisco Beltrão - PR, que apresenta dados relativos à situação educacional, econômica e social da população, bem como informações coletadas 
junto aos arquivos da Secretaria Municipal de Educação ${ }^{3}$ e por meio de questionários enviados às secretarias das escolas que compõem a rede pública, sendo que estes últimos propiciaram o levantamento dos dados indisponíveis na Secretaria Municipal de Educação.

Este artigo está assim estruturado: inicialmente realiza-se uma breve discussão teórica acerca da educação escolar; em seguida, a análise se centrará nas questões relativas à Formação de Professores e Rendimento Escolar para compreender se o processo de universalização ocorreu concomitante a garantia da qualidade.

Desvelar a problemática que permeia a relação quantidade $X$ qualidade na educação na sociedade capitalista, buscando instrumentos que ampliem as possibilidades de acesso e qualidade à escola pública, é fundamental para superar os desafios educacionais do contexto atual. Assim, vale considerar o que ressalta Saviani apud Orso (2007), "os antagonismos da sociedade de classes colocam desafios à educação: impossibilidade da universalização efetiva da escola e impossibilidade do acesso de todos ao saber; impossibilidade de uma educação unificada" (SAVIANI apud ORSO, 2007, p. $18)$.

\section{Uma breve discussão teórica acerca da educação escolar}

Tendo em vista o objetivo de compreender e analisar criticamente a situação educacional do município de Francisco Beltrão - PR no que concerne à formação de professores e ao rendimento escolar, serão inicialmente elencados alguns elementos teóricos pertinentes à temática.

É consenso o entendimento de que a educação escolar é um bem indispensável à formação humana na constituição da sociedade atual. Nos diferentes espaços de sociabilidade, é comum a afirmativa que reforça a necessidade social de que todas as pessoas passem pelos processos formais de escolarização. Entretanto, faz-se necessário compreender qual é a finalidade dos processos de escolarização, e que tipo de conhecimento se preconiza.

No tratamento desta questão, Saviani (2003) afirma que houve uma mudança significativa na importância atribuída à educação escolar na passagem do modo de produção feudal (regido pelo direito consuetudinário), para o capitalista (regido pelo direito positivo). O direito positivo, diferente do consuetudinário, requer a apropriação da leitura e da escrita de todos os participantes da sociedade, pois as leis que regem o convívio social são registradas na forma escrita. Segundo o autor,

Esse tipo de sociedade [a capitalista] tem, pois, como pressuposto, como premissa necessária, a introdução de códigos de comunicação não naturais, não espontâneos. É a partir daí que se pode entender a exigência de generalização dos códigos escritos, trazendo consigo, por consequência, a necessidade da generalização da alfabetização. Sobre esse pressuposto também se coloca a questão da universalização da escola que, estando referida ao trabalho intelectual, à cultura letrada, se constitui como via de acesso aos códigos escritos. Nas formas de sociedade anteriores, a escola podia ficar restrita àquela pequena parcela da sociedade que precisava desenvolver esse tipo de trabalho. A sociedade capitalista, cujo eixo passa a girar em torno da cidade, incorpora, na própria forma de organização, os códigos escritos, gerando a necessidade de que todos possam dominá-los. Decorre daí a proposta de universalização da escola e é sobre essa base que vão se estruturar os currículos escolares (SAVIANI, 2003, p. 134-135). 
É preciso ponderar, entretanto, que a significativa ampliação do acesso aos bancos escolares por parte da classe trabalhadora não significou o acesso pleno aos conhecimentos historicamente acumulados, tendo em vista a finalidade que a escola de massa vem cumprindo nesse processo, que se constitui na formação para o trabalho, numa perspectiva unilateral:

\begin{abstract}
Assim, a contradição do capitalismo atravessa também a questão relativa ao conhecimento: se essa sociedade é baseada na propriedade privada dos meios de produção e se a ciência, como conhecimento, é um meio de produção, deveria ser propriedade privada da classe dominante. No entanto, os trabalhadores não podem ser expropriados de forma absoluta dos conhecimentos, porque, sem conhecimento, eles não podem produzir e, se eles não trabalham, não acrescentam valor ao capital. Desse modo, a sociedade capitalista desenvolveu mecanismos através dos quais procura expropriar o conhecimento dos trabalhadores e sistematizar, elaborar esses conhecimentos, e devolvê-los na forma parcelada (SAVIANI, 2003, p. 137).
\end{abstract}

Como afirma Duarte (2001), uma das ilusões que vem sendo difundida pelo paradigma da sociedade do conhecimento consiste na crença de que o "conhecimento nunca esteve tão acessível como hoje, isto é, vivemos numa sociedade na qual o acesso ao conhecimento foi amplamente democratizado pelos meios de comunicação, pela informática, pela internet, etc." (DUARTE, 2001, p. 39).

Cabe questionar, corroborando com Duarte (2001), a afirmação de que o acesso ao conhecimento tenha sido de fato democratizado, tendo em vista a constatação de que a sociedade não rompeu com a divisão de classes, e logo, não se produziu condições efetivas de acesso pleno aos bens socialmente produzidos, dentre eles, o conhecimento científico. No que concerne aos conhecimentos acessíveis à classe trabalhadora, cabe ainda inferir a validade dos mesmos em proporcionar a possibilidade de emancipar os sujeitos enquanto seres livres e plenos da capacidade de integrar e realizar-se enquanto homens nesta sociedade. O pós-modernismo, paradigma da sociedade contemporânea, caracteriza-se entre outros aspectos, pelo ferrenho questionamento da capacidade do conhecimento científico constituir-se enquanto necessidade para o desenvolvimento pleno das capacidades humanas:

Para ultrapassar o caráter totalitário e obsoleto do paradigma de conhecimento moderno, o paradigma prudente ou o conhecimento científico proposto pela pós-modernidade deveria contribuir para a felicidade dos indivíduos e a definição, portanto, de um paradigma social (ZANARDINI, 2007, p. 255).

Para enfatizar a análise, Zanardini (2007) referencia Santos (2003):

[...] Santos (2003, p. 18) fala da necessidade de "[...] perguntar pelo papel de todo o conhecimento científico acumulado no enriquecimento ou no empobrecimento prático das nossas vidas, ou seja, pelo contributo positivo ou negativo da ciência para a nossa felicidade". Para apresentar um "contributo positivo", o conhecimento deveria partir do senso comum e romper com ele, transformando-se num "[...] novo e mais esclarecido senso comum" (SANTOS, 2003, apud ZANARDINI, 2007, p. 255). 
Assim, o conhecimento a ser disseminado a todos parece passar por um processo de regulação, ou seja, "não é qualquer conhecimento" que pode ser acessível a todos, mas apenas e dosadamente o conhecimento útil aos ditames do capital, mantendo a estrutura de classes, aliado a uma formação que garanta a produção e a reprodução do sistema. É a produção material da sociedade que determina como as pessoas que vivem nessa sociedade sejam formadas, daí a dificuldade de se vislumbrar outras perspectivas formadoras enquanto não for alterada o modo como a produção material se organiza. Neste sentido, Vázquéz (2007) afirma que

[...] essa libertação da produção material não pode ser assegurada - como sustentam hoje alguns adoradores do progresso tecnológico ou panegiristas da "sociedade industrial única" - sem se contar com o papel determinante que, nessa libertação, desempenham as relações sociais de produção. A transformação da natureza pelo homem não pode ser isolada da transformação do próprio homem; isto é, a práxis produtiva material seu destino como condição necessária do reino da liberdade de que fala Marx - não pode ser separada das relações sociais que selam seu destino; serão novas relações de produção as que determinarão que a libertação da produção material não se converterá em fonte de novos encadeamentos e alienações. Só elas permitirão que o tempo liberado da produção seja um verdadeiro tempo livre; isto é, que a exclusão do indivíduo da participação direta do processo produtivo material sirva precisamente para assegurar o desenvolvimento da capacidade criadora dos homens em outro terreno: artístico, científico, social, etc. (VÁZQUES, 2007, p. 399).

Esta pesquisa revela que os índices educacionais do município de Francisco Beltrão - PR melhoraram significativamente durante o período de 1988 a 2006, o que não significa necessariamente que tenha ocorrido a aproximação da emancipação humana nesse processo. Demonstra que o capital foi capaz de produzir uma instituição - escola - que tem dado conta das suas necessidades de sociabilidade, que por um lado garantem uma formação dos trabalhadores para a exploração, e de outro, não questionam a estrutura de classes desta sociedade. Assim, os mecanismos de controle do desempenho educacional desenvolvidos pelo Estado brasileiro têm cumprido com a função de assegurar que os fins da educação burguesa se efetivem.

\section{A formação de professores}

Focando a questão educacional, seguiram-se muitas ações que deveriam permitir a garantia de direitos, citando entre elas, a LDB 9394/96 e nesta, no que se refere à regulamentação da formação de professores e ao rendimento escolar, que entre outros elementos, retratam aspectos referentes à meta da CF 1988, no que tange a universalização do ensino.

Vale ressalvar que neste período houve uma considerável dinamização do lócus de formação do profissional da educação, concedida pela própria LDB 9394/96:

Art. 62. A formação de docentes para atuar na educação básica far-se-á em nível superior, em curso de licenciatura, de graduação plena, em universidades e institutos superiores de educação, admitida, como formação mínima para o exercício do magistério na educação infantil e nas quatro primeiras séries do ensino fundamental, a oferecida em nível médio, na modalidade Normal. (Regulamento) 
$\S 1^{\circ}$ A União, o Distrito Federal, os Estados e os Municípios, em regime de colaboração, deverão promover a formação inicial, a continuada e a capacitação dos profissionais de magistério. (Incluído pela Lei n ${ }^{\circ}$ 12.056, de 2009).

$\S 2^{\circ}$ A formação continuada e a capacitação dos profissionais de magistério poderão utilizar recursos e tecnologias de educação a distância. (Incluído pela Lei n ${ }^{\circ} 12.056$, de 2009).

$\S 3^{\circ} \mathrm{A}$ formação inicial de profissionais de magistério dará preferência ao ensino presencial, subsidiariamente fazendo uso de recursos e tecnologias de educação a distância. (Incluído pela Lei $\mathrm{n}^{\circ}$ 12.056, de 2009) (BRASIL, 1996).

Neste sentido, a formação estende-se e se amplia para diferentes esferas, inclusive as instituições privadas de ensino, mudando o tempo de formação, com significativa redução deste, mediante modalidade a distância.

O problema não está centrado na ampliação da oferta do lócus de formação, mas na qualidade desta formação, pois o que seria ganho, transformou-se em problema, devido ao aligeiramento dos processos formativos, com propostas que não garantiram uma sólida base teórico-metodológica em seus currículos, e que consequentemente provocaram a desqualificação.

Assim, de acordo com o que estabelece a lei suprema da educação, em vigor desde 1996, o professor, trabalhador da educação, tem garantida a sua qualificação profissional em serviço, podendo contar inclusive com licenciamento remunerado e progressão funcional. Ao passo que a lei abre esta possibilidade para a qualificação profissional, também a dificulta, ao ampliar a carga horária de 180 para 200 dias letivos e/ou 800 horas, pois nos calendários acadêmicos esta formação/qualificação, denominada de formação continuada, que deveria se efetivar em serviço, fica inviabilizada. Neste caso, o que se oferece aos professores, são cursos que extrapolam a carga horária de trabalho, sendo em fins de semana, ou em períodos fora do trabalho. Por vezes, quando ofertada em tempo de trabalho, faz-se manobras para não dispensar os alunos, o que nem sempre legitima na ampliação de dias letivos a melhoria da qualidade da educação.

Infelizmente não foi possível identificar se houve ou não um processo de ampliação do número de profissionais atuando na educação, pois, como já mencionado, a sistematização das informações por parte da Secretaria Municipal de educação do município é uma prática muito recente. Entretanto, no que refere à qualificação destes profissionais, ainda que de forma precária, pode-se levantar alguns dados que revelam como o município passou a assegurar as determinações da LDB 9394/96 no que se refere a formação de professores.

Os dados de 1988 e 1991 foram fornecidos pelas escolas municipais e são parciais, pois algumas escolas não devolveram os questionários e também porque não houve acesso às informações referentes à formação de professores das mais de 90 escolas rurais que foram fechadas. Mesmo assim, serão utilizados os dados coletados no sentido de fazer um comparativo da formação dos profissionais e a respectiva evolução nestes dois períodos. Os dados de 2001 foram fornecidos pela Secretaria de Recursos Humanos ${ }^{4}$. E os dados de 2008 referem-se aos fornecidos pela Secretaria de Educação, tendo em vista que desde 2005 este órgão passou a sistematizar este tipo de informação. 
FORMAÇÃO DE DOCENTES DA REDE PÚBLICA MUNICIPAL DE FRANCISCO BELTRÃO

\begin{tabular}{|l|l|l|l|l|l|}
\hline Ano Letivo & $\begin{array}{l}\text { Professor não } \\
\text { habilitado* }\end{array}$ & Magistério & Superior & Especialização & Total \\
\hline $1988^{* *}$ & 7 & 62 & 14 & 4 & 87 \\
\hline $1991^{* *}$ & 5 & 128 & 48 & 7 & 188 \\
\hline $2001 * *$ & 35 & 206 & 77 & 124 & 442 \\
\hline $2008 * *$ & & & & 360 & 443 \\
\hline
\end{tabular}

*Aqui relacionados os que apresentam como nível de formação o ensino fundamental ou o ensino médio em cursos diferentes do magistério.

**O número de escolas consultadas em cada ano é o seguinte: 1988 = dados de 8 escolas; $1991=$ dados de 12 escolas; 2001 e 2008 = dados de todas as escolas municipais.

Obs.: dados referentes a docentes da rede, incluindo os que atuam na pré-escola ofertada nas escolas municipais de ensino fundamental.

Os índices apresentados revelam, do ponto de vista amostral, um aumento do índice de qualificação dos profissionais docentes que atuam nas séries iniciais do ensino fundamental da rede municipal. Considerando que em 1988, dos 87 professores que compõem a amostra apenas 4 pessoas $(4,3 \%)$ tinham curso de especialização e que, em 2008, dos 443 professores do município, 360 cursaram especialização (82\%). Assim, é preciso reconhecer que houve significativo avanço. Entretanto, contraditoriamente, alguns profissionais continuaram atuando como docentes sem habilitação, pois ainda em 2001, 35 profissionais (8\%) atuavam sem a devida formação. No conjunto da ampliação deste processo de qualificação, a maior oferta de cursos ocorre na rede privada de ensino superior, mais especificamente nos cursos oferecidos a distância.

A rede pública de ensino oferece todos os anos 40 vagas para a formação no nível médio (magistério no Col. Estadual Mário de Andrade) e 90 vagas para a formação no ensino superior (Pedagogia na Universidade Estadual do Oeste do Paraná - UNIOESTE). A Universidade do Paraná - UNIPAR oferece cursos de licenciatura em História e Ciências Biológicas.

Por outro lado, a oferta de cursos de formação de professores a distância é vasta e compreende diferentes níveis. Ao todo, são 621 vagas que abrem todos os anos, distribuídos nas seguintes instituições: IESDE/Colégio Bagozzi (Curso Normal a Distância; 160 vagas); Universidade Eletrônica do Paraná (Curso Normal Superior; 140 vagas); IESDE/VIZIVALE (Programa de Formação Docente em Nível Superior; 230 vagas); ULBRA - DP Consultoria (Pedagogia; 40 vagas); FACINTER - CBED (Normal Superior; 25 vagas); EDUCON (Pedagogia, 26 vagas) (FRANCISCO BELTRÃO, 2007, p. 99).

Depreender-se assim, que a tarefa legal (CF 1988 e LDB 9394/96), vem se efetivando e que paralelamente a isso, que deveria significar a qualificação do profissional da educação, vem se acentuando a desqualificação, agregando-se a isso a desvalorização, os baixos salários, a ausência de melhorias nas condições trabalho, e que a "[...] proletarização é percebida como um processo inerente à desqualificação e precarização do trabalho docente, em decorrência das mudanças ocorridas na sociedade capitalista e, como consequência, no processo de trabalho do professor" (TUMOLO e FONTANA, 2008, p.164).

\section{Sobre o rendimento escolar}

No que tange ao rendimento escolar, na LDB 9394/96 se estabelece no art. $9^{\circ}$, referente à organização nacional da educação, à União a incumbência de assegurar 
processo nacional de avaliação do rendimento escolar no ensino fundamental, médio e superior, em colaboração com os sistemas de ensino, objetivando a definição de prioridades e a melhoria da qualidade do ensino (inciso VI). No artigo 12, a LDB determina que os estabelecimentos de ensino, respeitadas as normas comuns e as do seu sistema de ensino, terão a incumbência de: a) prover meios para a recuperação dos alunos de menor rendimento (inciso $\mathrm{V}$ ); b) informar os pais e responsáveis sobre a frequência e o rendimento dos alunos, bem como sobre a execução de sua proposta pedagógica (inciso VII).

Mais adiante, no Art. 13, a LDB prescreve que os docentes incumbir-se-ão de: a) III - zelar pela aprendizagem dos alunos (inciso III) e b) estabelecer estratégias de recuperação para os alunos de menor rendimento (inciso IV).

A LDB, ao regulamentar a estrutura e o funcionamento da educação básica, determina, no seu art. 23, que a educação básica poderá organizar-se em séries anuais, períodos semestrais, ciclos, alternância regular de períodos de estudos, grupos nãoseriados, com base na idade, na competência e em outros critérios, ou por forma diversa de organização, sempre que o interesse do processo de aprendizagem assim o recomendar. Este princípio de flexibilidade de organização curricular orienta também, no inciso $\mathrm{V}$ do artigo 23, que a verificação do rendimento escolar observará os seguintes critérios: a) avaliação contínua e cumulativa do desempenho do aluno, com prevalência dos aspectos qualitativos sobre os quantitativos e dos resultados ao longo do período sobre os de eventuais provas finais; b) possibilidade de aceleração de estudos para alunos com atraso escolar;

e c) obrigatoriedade de estudos de recuperação, de preferência paralelos ao período letivo, para os casos de baixo rendimento escolar, a serem disciplinados pelas instituições de ensino em seus regimentos.

Neste sentido, o que se estabelece, de forma bastante ampla na LDB 9394/96, parece permitir as instituições de ensino deliberarem sobre questões relativas à avaliação, tanto institucional, como do ensino - aprendizagem, conforme seus projetos políticospedagógicos. No entanto, deixa claro que cabe a União avaliar nacionalmente o ensino, em todos os níveis e modalidades, por uma "subjetiva" objetivação de prioridades para a melhoria da qualidade de ensino. Evidencia-se neste processo que a

[...] padronização dos programas de ensino e dos currículos escolares contribuiu para uma diminuição na participação do professor no resultado do seu trabalho, já que estas regulamentações influenciam no conteúdo que o professor deve ensinar e em como ele irá ensinar (TUMOLO e FONTANA, 2008, p. 164)

Então, o que se pode diagnosticar, é que na avaliação do rendimento escolar, pelos mecanismos externos a escola, como exemplo pelo Saeb, na Provinha Brasil $1^{5}$, os resultados aferidos, estão servindo muito mais para classificar e fazer comparações entre escolas, do que para agregar esforços em trabalhar as fragilidades do sistema que também são responsáveis pelos índices. Assim, pela avaliação, acaba por se efetivar o que ressalva Libâneo (2004):

Os rumos que as práticas avaliativas vêm tomando no âmbito do sistema de ensino brasileiro, ao contrário da posição formulada anteriormente, encaminham-se para a subordinação do trabalho dos professores e, portanto, da avaliação do sistema. Nesse caso, não são os objetivos do ensino que irão determinar as formas de avaliação, mas a avaliação é que 
acabará por determinar os objetivos, ou seja, dependendo das finalidades postas pelos governos em relação à avaliação do sistema de ensino, ter-se à uma escola funcional a serviço dos interesses de agências externas à escola (Libâneo, 2004, p.240).

No ano de 2007 o desempenho do município de Francisco Beltrão - PR no Índice de Desenvolvimento da Educação Básica - IDEB, que mede o desempenho educacional das escolas através dos resultados obtidos pelos alunos na Prova Brasil ${ }^{6}$ e no senso escolar (onde são considerados os índices de reprovação e evasão) supera largamente a média nacional: enquanto o município atingiu o desempenho de 5,2, a média nacional ficou em 4,2. Alunos de 12 das 21 escolas participaram da Prova, que obteve rendimento médio de 4,2 (numa escala que vai a 10) (BRASIL, 2007).

A LDB 9394/96, como dito anteriormente, parece permitir as instituições de ensino deliberarem sobre questões relativas a avaliação, tanto institucional, como do ensino e aprendizagem, conforme seus projetos políticos-pedagógicos, o que, na verdade acaba sendo um engodo e engessando as possibilidades de avanços qualitativos na educação. Diante deste contexto,

A avaliação pode deixar de ser o que é para se transformar em outra modalidade de trabalho institucional, essa transformação só pode ocorrer a nível da escola; só pode ocorrer caso a escola, cooperativamente, proponha-se a assumir as questões a serem mudadas. A mudança de perspectiva da avaliação só acontecerá quando os professores de uma coletividade se propuserem, por intencionalidade conjunta, a rever a forma de trabalho atual face a critérios comuns de análise da sociedade e da escola (NAGEL, 1985, p. 28).

A avaliação expressa, a partir do rendimento escolar, um determinado projeto educacional. Se tomados esses dados como parâmetro para análise do processo de universalização da educação, os dados da tabela abaixo revelam como o Município de Francisco Beltrão - PR vem melhorando quantitativamente seus índices.

RENDIMENTO ESCOLAR DO ENSINO FUNDAMENTAL (ANOS INICIAIS) DO MUNICÍPIO DE FRANCISCO BELTRÃO

\begin{tabular}{|c|c|c|c|c|c|}
\hline ANO & MATRÍCULAS & APROVAÇÕES & REPROVAÇÃO & EVASÃO & TRANSFERÊNCIAS $* * *$ \\
\hline $1988^{*}$ & 5106 & 2222 & 850 & 572 & - \\
\hline 1989* & 5142 & 1908 & 985 & 592 & - \\
\hline 1990* & 4966 & 2293 & 856 & 500 & - \\
\hline $1991 *$ & 6522 & 3178 & 1024 & 625 & - \\
\hline $1992 *$ & 6460 & 3191 & 888 & 691 & - \\
\hline 1993* & 6697 & 3754 & 587 & 667 & - \\
\hline $1994 *$ & 7374 & 5656 & 87 & 487 & - \\
\hline $1995^{*}$ & 7392 & 5544 & 219 & 429 & - \\
\hline $1996^{*}$ & 7922 & 5878 & 317 & 389 & - \\
\hline $1997 *$ & 7240 & 5067 & 331 & 400 & - \\
\hline 1998 & 6160 & 4927 & 164 & 84 & 985 \\
\hline 1999 & 5964 & 4810 & 185 & 81 & 888 \\
\hline 2000 & 5777 & 4579 & 250 & 60 & 888 \\
\hline 2001 & 6302 & 5147 & 245 & 65 & 845 \\
\hline 2002 & 6092 & 4769 & 438 & 53 & 834 \\
\hline 2003 & 6330 & 4737 & 547 & 59 & 968 \\
\hline 2004 & 6212 & 5600 & 575 & 74 & 943 \\
\hline 2005 & 6042 & 4648 & 442 & 21 & 733 \\
\hline 2006 & 6150 & 4894 & 335 & 9 & 912 \\
\hline
\end{tabular}


FONTE: Secretaria Municipal de Educação de Francisco Beltrão.

*As informações relativas aos anos de 1988 a 1997 são parciais, pois, no referido período a Secretaria Municipal de Educação não produziu relatórios da situação educacional no município. Assim, o levantamento aqui apresentado foi realizado com base nos relatórios anuais das escolas extintas, cujos arquivos foram consultados individualmente. As escolas em funcionamento mantêm tais dados arquivados em suas respectivas secretarias, os quais foram solicitados por meio de formulários. Das 21 escolas atualmente existentes, 14 retornaram os formulários.

** Não constam informações relativas a transferências do período de 1988 a 1997. Tais informações só passaram a ser sistematizadas a partir de 1998, quando as escolas passam a adotar o Sistema de Registro Escolar - SERE, por meio do qual cada aluno passa a ter um cadastro individual. Note-se, que aparentemente há uma redução no número de matrículas a partir de 1998, o que na verdade revela que cada vez que o aluno é transferido dentro do município ou estado, não é contabilizado como matrícula nova, pois leva para a nova escola o mesmo registro do SERE.

De acordo com o Instituto Brasileiro de Geografia e Estatística - IBGE (IPARDES, 2009), em 2008, o município de Francisco Beltrão - PR tinha 6.266 alunos matriculados no ensino fundamental nas 21 escolas municipais, onde atuavam 287 docentes.

Analisando os dados do rendimento escolar, verifica-se que no ano de 1988, o município de Francisco Beltrão - PR contava com 93 escolas, com 5.106 alunos matriculados, sendo que destes 572 evadiram da escola, 850 reprovaram e 3.644 alunos foram concluintes. Se comparados estes índices ao ano de 2006, constata-se que haviam 21escolas, sendo que nestas haviam 6150 matriculados, dos quais 572 evadiram da escola, 339 reprovaram e 4.894 foram concluintes.

Diante desta constatação, pode-se inferir que os dados deixam transparente a ampliação dos números de matriculados nas escolas municipais e de concluintes, o que significa redução de evasão e reprovação, e, validados os índices quantitativos, melhoria no rendimento escolar. No entanto, é preciso ponderação ao diagnosticar os índices relativos a evasão e repetência, pois os mesmos ainda permanecem significativos, e, no que concerne a universalização, significam comprometimento do rendimento $\mathrm{e}$ consequentemente da melhoria da qualidade. Diante deste contexto, como indicado anteriormente na análise sobre a formação docente, as melhorias nos índices quantitativos nem sempre revelam melhorias qualitativas.

\section{Considerações finais}

Neste artigo realizou-se uma análise crítica da formação de professores e do rendimento escolar nas séries iniciais do ensino fundamental da rede pública municipal no período de 1988 a 2006 do município de Francisco Beltrão-PR . Dentre as constatações que podem ser indicadas, cabe mencionar a dificuldade de encontrar os dados na Secretaria Municipal de Educação.

Atualmente, muitas pesquisas em História da Educação alertam sobre a necessidade e urgência em fazer a preservação de arquivos e fontes primárias e secundárias nas escolas. No contexto da história educacional brasileira, muito já se perdeu em decorrência de fragilidade com que se encontram as fontes documentais da escola. Com frequência pode-se diagnosticar, documentos institucionais perdidos ou mal guardados entre poeira e traças em arquivos mortos das escolas, normalmente localizados em salas pequenas, úmidas e sem ventilação. Assim, muito da história educacional se perdeu, o que inclusive impossibilita pesquisas na área.

Dessa forma, evidencia-se a necessidade urgente do envolvimento das escolas, secretarias de educação e de seus profissionais com a preservação da memória institucional da Escola Pública, pois "homens produziram (e ainda produzem) artefatos, documentos, testemunhos, monumentos entre outros, que tornam possível o entendimento do homem sobre sua própria trajetória" (LOMBARDI e NASCIMENTO, 2004, p. 155-6).

Apesar das dificuldades encontradas na coleta de dados, no plano formal, constatase que a educação pública oferecida à população no município de Francisco Beltrão - PR 
está assentada aparentemente numa situação que se avizinha da perfeição: grande parte dos professores está bem qualificada, e o município apresenta resultados que superam a média nacional nos exames de avaliação e rendimento escolar.

A formação do professor tem relação direta com o rendimento escolar e consequentemente, na qualidade da educação. Resta então questionar: que formação é essa que prioriza a quantidade em detrimento da qualidade?

Alves (2007), ao tratar dos processos de qualificação profissional, apresenta a tese de que os próprios cursos de qualificação passam a constituir um mercado, o que não é diferente quando o assunto é formação de professores. Seguindo esta lógica, as "novas qualificações/habilitações da força de trabalho, assumem formas fetichizadas, se impondo a todos e a todas, e frustrando suas expectativas de realização humano-genérica" (ALVES, 2007, p. 9).

A divulgação dos dados do IDEB acaba por fazer com que muitas escolas, preocupadas em atingir resultados satisfatórios nos índices, desconsiderem os seus projetos políticos-pedagógicos, voltando suas práticas pedagógicas às demandas destas avaliações externas. Em contato com diversas escolas do município, pode-se constatar que muitas escolas estavam centradas em conteúdos de Língua Portuguesa e Matemática, com tempo ampliado e reduzindo conteúdos das demais áreas de conhecimento, pois precisavam "preparar as crianças para a Provinha Brasil". Vários elementos poderiam ser questionados nesta decisão pedagógica, pela tamanha complexidade e gravidade nela contida, porém de imediato fica clara a compreensão e a prática de um conteúdo ensinado de forma fragmentada, como se a Geografia, a História, entre outras disciplinas, não pudessem trabalhar Língua Portuguesa e Matemática e fossem menos importantes. Conforme Saviani (2008), este fenômeno revela que

Estamos, pois, diante de um neotecnicismo: o controle decisivo deslocase do processo para os resultados. É pela avaliação dos resultados que se buscará garantir a eficiência e a produtividade. E a avaliação converte-se no papel principal a ser exercido pelo Estado, seja mediatamente, pela criação das agências reguladoras, seja diretamente, como vem ocorrendo no caso da educação. Eis por que a nova LDB [...] enfeixou no âmbito da União a responsabilidade de avaliar o ensino em todos os níveis, compondo um verdadeiro sistema nacional de avaliação. E para desincumbir-se dessa tarefa o governo federal vem instituindo exames e provas de diferentes tipos. Trata-se de avaliar os alunos, as escolas, os professores e, a partir dos resultados obtidos, condicionar a distribuição de verbas e a alocação dos recursos conforme os critérios de eficiência e produtividade (SAVIANI, 2008, p. 439).

Portanto, o trabalho pedagógico tem sido norteado pelos exames nacionais de avaliação, inferindo-se assim, que a lógica capitalista determina a constituição das políticas educacionais, as quais resultam na perpetuação da lógica excludente em detrimento de uma formação humana emancipatória. Entretanto, novas práticas educativas não surgirão de outra sociedade, mas no seio desta mesma sociedade dividida em classes, antagônica e excludente. À educação nesse processo, compreende

a tarefa de uma transformação social, ampla e emancipadora. Nenhuma das duas pode ser posta à frente da outra. Elas são inseparáveis. A transformação social emancipadora radical requerida é inconcebível sem uma concreta e ativa contribuição da educação (MÉSZÁROS, 2005, p. 76). 


\section{Bibliografia}

ALVES, Giovanni. Reestruturação produtiva, novas qualificações e empregabilidade. In: Dimensões da Reestruturação Produtiva - Ensaios de Sociologia do Trabalho. Londrina - PR, Editora Práxis, 2007.

BRASIL. CONSTITUÇÃO FEDERAL DE 1988. Disponível em:

$<<\quad$ http://www.planalto.gov.br/ccivil_03/constituicao/constitui\%C3\%A7ao.htm >>. Acessado em 10/11/2009.

EMENDA CONSTITUCIONAL No 14, DE 12 DE SETEMBRO DE 1996. Modifica os arts. 34, 208, 211 e 212 da Constituição Federal e dá nova redação ao art. 60 do Ato das Disposições constitucionais Transitórias. Disponível em:

<<http://www.planalto.gov.br/ccivil_03/Constituicao/Emendas/Emc/emc14.htm >>. Acessado em 10/11/2009.

IDEB - Índice de Desenvolvimento da Educação Básica. Consulta ao índice nacional e ao do município de Francisco Beltrão, 2007.

Disponível em:

<<http://ideb.inep.gov.br/Site/>> Acessado em 10/11/2009.

LDB - Lei de Diretrizes e Bases da Educação Nacional. Aprovada pela lei 9.393 em 20 de dezembro de 1996.

Disponível em: <<http://www.planalto.gov.br/ccivil_03/LEIS/19394.htm>>.

DUARTE, Newton. As pedagogias do "aprender a aprender" e algumas ilusões da assim chamada sociedade do conhecimento. Revista Brasileira de Educação. Set/dez. n. 018. Associação Nacional de Pós-Graduação e Pesquisa em Educação. São Paulo, 2001. p. $35-40$.

FRANCISCO BELTRÃO. Secretaria Municipal de Educação. Plano Municipal de Educação. Aprovado pela Lei N ${ }^{\circ}$ 3336/2007, em 19 de abril de 2007.

IPARDES - Instituto Paranaense de Desenvolvimento Econômico e Social. Caderno Estatístico: Município de Francisco Beltrão. Outubro de 2009. Disponível em:

$<<$ http://www.ipardes.gov.br/cadernos/Montapdf.php?Municipio=85600 $>>$. Acessado em: 09/11/2009.

LIBÂNEO, J. C. Organização e gestão da escola: teoria e prática. 5. ed. Goiânia; Alternativa, 2004.

LOMBARDI, J. C.; NASCIMENTO, M. I. M. (orgs.). Fontes, História e Historiografia da Educação. Campinas, SP: Autores Associados: HISTEDBR; Curitiba, PR: PUCPR; Palmas, PR: UNICS; Ponta Grossa, PR: UEPG, 2004. p. 3 - 12.

MÉSZÁROS, István. A educação para além do capital. São Paulo: Boitempo, 2005.

NAGEL, Lizia Helena. Avaliação, sociedade e escola: fundamentos para reflexão. Curitiba, Secretaria de Estado da Educação - SEED/PR, 1985.

SAVIANI, Dermeval. Os desafios da educação pública na sociedade de classes. In: ORSO, P.J. ( Org.). Educação, sociedade de classes e reformas universitárias. Campinas, SP: Autores Associados, 2007.

História das ideias pedagógicas no Brasil. 2. ed. Campinas, SP: Autores 
Associados, 2008. 152. 2003.

O choque teórico da politecnia. Revista Trabalho, Educação e Saúde. 1 (1): 131-

TUMOLO, Paulo Sergio; FONTANA, Klalter Bez. Trabalho docente e capitalismo: um estudo crítico da produção acadêmica da década de 1990. In.: Revista Educação e Sociedade, vol. 29, num. 102, jan-abr, 2008, pp. 159-180.

VÁSQUEZ, Adolfo Sánchez. Filosofia da Práxis. 1 ed. Buenos Aires: Consejo Latinoamericano de Ciencias Sociales - CLACSO; São Paulo: Expressão Popular, Brasil, 2007 (Traducido por María Encarnación Moya).

ZANARDINI, Isaura Monica S. A reforma do Estado e da Educação no contexto da ideologia da pós-modernidade. Revista Perspectiva. v.25. p.245 - 270. Florianópolis, 2007.

\section{Notas:}

1 A pesquisa da qual este artigo é resultado foi realizada a convite do Grupo de Estudos e Pesquisas em Política Educacional e Social - GEPPES, linha de Pesquisa Política Educacional, da Universidade Estadual do Oeste do Paraná, Campus de Cascavel. Faz parte da pesquisa: "Gestão de políticas públicas de educação em municípios do oeste e sudoeste do Paraná: avaliação dos resultados das políticas públicas de educação (séries iniciais do ensino fundamental) (1988-2006)", que envolve os municípios de Cascavel, Foz do Iguaçu, Francisco Beltrão, Toledo e Marechal Cândido Rondon, e conta com apoio financeiro da Fundação Araucária.

${ }^{2}$ Fundo de Manutenção e Desenvolvimento do Ensino Fundamental e de Valorização do Magistério FUNDEF foi instituído pela Emenda Constitucional n..$^{\circ}$ 14, de setembro de 1996.

${ }^{3}$ Como já mencionado, a Secretaria Municipal de Educação não tinha, até 1998, como prática coletar, registrar e arquivar dados relativos ao número de professores e sua respectiva formação; tampouco as informações no que tange à matrícula, rendimento e evasão dos alunos. Sendo assim, a alternativa encontrada para resgatar tais informações foi a de enviar questionários às escolas municipais, solicitando os referidos dados. Entretanto, faltavam os dados das escolas rurais existentes em 1988 as quais foram sendo fechadas gradativamente e tiveram seus relatórios anuais arquivados na Secretaria Municipal de Educação, os quais foram pesquisados e considerados neste trabalho.

${ }^{4}$ Uma funcionária da Secretaria de Recursos Humanos nos informou que todos os anos são feitas atualizações sem que os dados gerados anteriormente sejam salvos. Os dados referentes a 2001 só foram preservados em razão de que neste ano o computador do órgão sofreu um problema técnico, de modo que os dados gerados até então tiveram que ser recuperados para dar origem a um novo banco de dados.

${ }^{5}$ A Provinha Brasil foi criada em 2008 pelo governo federal para diagnosticar o nível de alfabetização dos alunos de $2^{\mathrm{a}}$. série do ensino fundamental. A prova é aplicada em dois momentos: no início do ano, para medir o grau de letramento dos alunos, e outra no final do ano, para medir o grau de evolução obtido no ano letivo (BRASIL, 2009).

${ }^{6}$ A Prova Brasil foi criada em 2005 e é aplicada a alunos de $4^{\mathrm{a}}$. e $8^{\mathrm{a}}$. séries do ensino fundamental (ou $5^{\mathrm{a}}$. e $9^{\text {a., }}$ no caso do ensino fundamental de 9 anos). Consiste na avaliação do desempenho quanto aos conhecimentos de português e matemática e é aplicada aos alunos estudantes de escolas urbanas. Junto com o Censo Escolar, a Prova Brasil é um dos itens que mede o Índice de Desenvolvimento da Educação Básica IDEB (BRASIL, 2009).

Recebido em: $\quad 15 / 02 / 11$

Aprovado em: $\quad 20 / 03 / 11$ 